\title{
Job satisfaction as a correlate of empathic behaviour among health care providers towards their patients
}

\author{
Patrick lyeke* \\ Institute of Education, Delta State University, Abraka, Nigeria
}

Received: June 17, 2020

Accepted: September 1, $2020 \quad$ Online Published: October 27, 2020

DOI: $10.5430 /$ ijh.v7n1p29

URL: https://doi.org/10.5430/ijh.v7n1p29

\begin{abstract}
This study examined the influence of job satisfaction on empathic behaviour of health care workers towards their patients. Four research questions and five hypotheses guided the study. The study is an ex-post facto research design that adopted the correlation method. A sample size of 1,200 health care workers was selected through a multi-stage sampling method. The method of data collection is a questionnaire, whose psychometric properties were adjudged to be adequate. A total of 1,114 copies were questionnaire were returned after administration and was used for data analysis. The analysis was done using Pearson's correlation and coefficient of determination for the research questions as well as regression and path analysis for the hypotheses at 0.05 alpha level. The result showed that job satisfaction is positively associated with emphatic behaviour of health care workers towards their patients. The study further revealed that the three components of job satisfaction; affective, cognitive and behavioural components were positively associated with emphatic behaviour and that gender does not moderate the influence of the three components of job satisfaction on empathic behaviour of health care workers towards their patients. Based on the findings, recommendations were made.
\end{abstract}

Key Words: Job satisfaction, Empathic behaviour, Health care workers, Affective, Cognitive, Behavioural

\section{INTRODUCTION}

Healthcare is a helping profession that focuses on improving the lives of people through building relationships and developing interactions to further a patient's well-being. As a result, healthcare professionals need to be prepared to treat an array of health issues in patients and work with all personality types. Working in a health facility is such a sensitive career one can venture into. This is because, it has to do with saving human lives, especially when one is involved directly in health practice. Life as a health care worker is full of mixed feelings. At times, one will be elated with the joy of new entrance into the world, at other times, one will feel so depressed at the agony and death of a patient. These and many others are the plights of a health worker, especially in a
Nigerian health facility, were good and word-class facilities are just a mirage. Sometimes the only thing that gets them going is the feeling of empathy.

Hojat, et al. defined empathy as a cognitive attribute that allows providers to understand and discuss a patient's inner experiences and perspective. ${ }^{[1]}$ It has to do with putting oneself in another's shoe. It allows one to notice the pain of others. Such a trait is highly needed in medical practice. This is because to be able to take care of a sick patient, the medical practitioner needs to be able to notice the pain of such a patient. According to Sudeh, et al. empathy captures compassion to both the informational and emotional aspects of provider-patient communication, so it is often seen as

*Correspondence: Patrick Iyeke; Email: iyekepatrick8@gmail.com; Address: Institute of Education, Delta State University, Abraka, Nigeria. 
crucial to the effective achievement of patient satisfaction. ${ }^{[2]}$

Figley suggests that the most effective therapists are those who utilize and expresses empathy and compassion. ${ }^{[3]}$ In sharing the client's suffering, the caregiver expresses compassion that in turn strengthens and comforts the sufferer. ${ }^{[4]}$ Further expanding the relevance of empathy in health care practice, Figley states that ".... they provide the tools required in the art of human service. To see the world as our clients see it enable us to calibrate our services to fit them and to adjust our services to fit how they are proceeding., ${ }^{[3]}$

One variable that is assumed to be related to empathy is job satisfaction. It the satisfaction one derives from his/her job. It refers to how people feel about their jobs and different aspects of their jobs. ${ }^{[5]}$ Ellickson and Logsdon ${ }^{[6]}$ refer to job satisfaction as the likeness people have towards their work. According to Schermerhorn, ${ }^{[7]}$ job satisfaction is an affective or emotional response towards various aspects of an employee's work. Reilly defines job satisfaction as the feeling that a worker has about his job or a general attitude towards work or a job and it is influenced by the perception of one's job. ${ }^{[8]}$ Wanous and Lawler refer to job satisfaction as the sum of job facet satisfaction across all facets of a job. ${ }^{[9]}$ Job satisfaction like attitude is made up of three components; affective, cognitive and behavioural components.

The affective component of job satisfaction refers to the feelings individuals have towards their job. It comprised positive affect (PA) and negative affect (NA). The positive effect of job satisfaction refers to the extent to which an individual feels enthusiastic, active, and alert. ${ }^{[10]}$ It is sometimes described as enjoying life and feeling fully engaged. ${ }^{[11]}$ According to Yik and Russell, ${ }^{[12]}$ people with high positive affect tend to be energetic, outgoing and extroverted. Supporting this view, Watson et al. opined that people with high positive affect exhibit social behaviour. ${ }^{[10]}$ They further explained that people with high positive affect are more satisfied with work and life in general as well as being sensitive to the frequency of rewards, suggesting they may orient towards the positive aspects of life. On the other hand, people with high negative affect tend to have a negative orientation toward life. ${ }^{[13]}$ According to Watson, et al., negative affect refers to the extent to which people experience "a general dimension of subjective distress and unpleasant engagement" that may take the form of many emotional states, "including anger, contempt, disgust, guilt, fear, and nervousness."[10] People high in NA report more physical complaints and more stress. ${ }^{[14]}$

The cognitive component of job satisfaction refers to the thoughts individuals have about their job usually in comparison to a standard or expectation. ${ }^{[15]}$ In corroborating this claim, Tekell explained that if an employee expects a certain level of autonomy in the way he works and is being micromanaged, the discrepancy between expected and perceived autonomy may lead to thoughts of dissatisfaction. ${ }^{[16]}$ They may be thought of as the rational, calculating part of attitudes that rely on unemotional comparisons. ${ }^{[17]}$

Sand found job satisfaction to be related to a high level of empathy among nursing staff. ${ }^{[18]}$ According to Larson and Yao ${ }^{[19]}$ empathic behaviour helps health workers to be more effective in their work. This according to them, creates a higher level of job satisfaction. Mousavi, et al. revealed that empathy is positively related to job satisfaction. ${ }^{[20]}$

Homburg and Stock state that in the case of employees with ongoing customer contact, employee job satisfaction is positively associated with customer satisfaction and that empathy is a moderator variable which strengthens the association between these two variables. ${ }^{[21]}$ This is because empathy improves communication between the employee and customer and creates a better relationship.

Empathy and job satisfaction can also be associated with the emotional well-being of staff. Lombardo and Eyre state that most nurses commence their career with a desire to provide empathetic care to patients, ${ }^{[22]}$ however, where the needs of the patient outweigh the nurse's capacity to meet those needs, the nurse can become a victim of continuing stress and compassion fatigue. This will then result in decreased job satisfaction and poor quality health services for the patient.

The discussion above has shown that empathy is a very important aspect of the job of health care workers. This is because a great deal of their job requires that they show empathic behaviour towards their patients. Empathic behaviour is associated with job satisfaction. The assumption is that individuals who are satisfied with their job are more likely to show empathic behaviour towards their patients. This assumption has not, however, be proven to be true or false, especially in a sample as health care workers in Delta State, Nigeria. It is based on this background that this study is aimed to examine the influence of job satisfaction on empathic behaviour among health care workers in Delta State, Nigeria.

\subsection{Research questions}

This study was guided by the following research questions:

(1) Will there be any relationship between job satisfaction and empathic among health care workers?

(2) Will there be a significant relationship between the affective component of job satisfaction and empathy among health care workers?

(3) Will there be a significant relationship between the 
cognitive component of job satisfaction and empathic behaviour among health care workers?

(4) Will there be a significant relationship between the behavioural component of job satisfaction and empathic behaviour among health care workers?

\subsection{Hypotheses}

The following null hypotheses were tested at 0.05 alpha level:

(1) There is no significant relationship between job satisfaction and empathy among health care workers

(2) There is no significant relationship between the affective component of job satisfaction and empathy among health care workers

(3) There is no significant relationship between the cognitive component of job satisfaction and empathic behaviour among health care workers

(4) There is no significant relationship between the behavioural component of job satisfaction and empathic behaviour among health care workers

(5) There is no significant moderating impact of gender on the relationship between affective, cognitive and behavioural components of satisfaction and emphatic behaviour among health care workers

\section{MethodS}

\subsection{Research design}

The study adopted a correlational method of ex-post-facto research design. The choice of correlational design was as a result of the fact that the study examined the relationship that exists among several variables.

\subsection{Population and sample}

The population comprised all health workers in Delta State, Nigeria, among whom, a total of 1,200 were sampled through a multistage sampling method. The first stage involved the stratification of each health facilities in Delta State by senatorial districts. The second stage involved the selection of health facilities across the three senatorial districts of Delta State, Nigeria through simple random sampling technique of the balloting method. In the third stage, the health workers in each of the selected health facilities were selected through purposive sampling technique. Through the purposive sampling technique, the researcher worked with only available health workers, who directly work with patients.

\subsection{Measures}

The instrument used for the collection of data was a questionnaire made up of two scales; job satisfaction rating scale and empathic behaviour rating scale. The questionnaire was developed by the researcher. The job satisfaction rating scale contained 30 Likert-type items, generated in line with the three components of job satisfaction; affective, cognitive and behavioural components. The empathic behaviour rating scale contained 15 Likert-type items. The questionnaire was structured on a 4-point scale, ranging from 1 for strongly disagree to 4 for strongly agree.

The instrument was validated through experts' judgement. The questionnaire was printed and handed over to experts in the field of Psychology as well as in Measurement and Evaluation. They assessed the appropriateness and suitability of the items in the questionnaire to the overall objectives of the study. Some of the items were removed while others amended to suit the objectives of the study.

The reliability of the instrument was estimated by administering the questionnaire to a group of health workers in Edo State, Nigeria, which is outside the study area. The data was analysed using the Cronbach alpha reliability coefficient and a coefficient of 0.92 and 0.89 was obtained for job satisfaction rating scale and empathic behaviour rating scale respectively. The questionnaire was administered directly by the researcher. A group of final year university students were recruited as research assistants, who were adequately sensitised on the objectives of the study as well as skills and ethical considerations in test administration.

\subsection{Administration of instrument}

The test administration took a period of 3 months, at the end of which, a total of 1,200 copies of questionnaire were administered, but only 1,114 copies were returned, indicating $92.83 \%$ retrieval rate.

\subsection{Data analysis}

The data obtained in the field were collated and entered into a computer system through the Statistical Package for Social Sciences (SPSS) version 22. Pearson's coefficient was used to answer the research questions while regression and path analysis were used to test the hypotheses at 0.05 alpha level.

\section{Results}

Research Question 1: Will there be any relationship between job satisfaction and empathic among health care workers?

From the result of Table 1, the coefficient of determination is 0.30 , which indicate a moderate positive relationship between job satisfaction and empathy among health care workers. The result has shown that job satisfaction accounted for $30 \%$ of the variance in empathic behaviour.

Research Question 2: Will there be a significant relation- 
ship between the affective component of job satisfaction and empathy among health care workers?

Table 1. Analysis of the relationship between job satisfaction and empathy among health care workers

\begin{tabular}{lllllll}
\hline Variable & $\mathbf{N}$ & Mean & SD & $\mathbf{r}$ & $\mathbf{r}^{2}$ & Decision \\
\hline Job Satisfaction & \multirow{2}{*}{14.32} & 0.45 & & & Moderate \\
Empathy & \multirow{2}{*}{3.85} & 0.44 & 0.55 & 0.30 & $\begin{array}{l}\text { Positive } \\
\text { Relationship }\end{array}$ \\
\hline
\end{tabular}

Table 2 shows a small positive relationship between the affective component of satisfaction and empathy among health care workers. This is shown in a coefficient of 0.15. As indicated in the coefficient of determination, the affective component of job satisfaction accounted for only $15 \%$ of the variance empathic behaviour.

Table 2. Analysis of the relationship between the affective component of job satisfaction and empathy among health care workers

\begin{tabular}{lllllll}
\hline Variable & $\mathbf{N}$ & Mean & SD & $\mathbf{r}$ & $\mathbf{r}^{2}$ & Decision \\
\hline $\begin{array}{l}\text { Affective Component } \\
\text { of Job Satisfaction }\end{array}$ & 1,144 & 3.52 & 0.44 & & & Small \\
Empathy & & 3.85 & 0.44 & & & Relationship \\
\hline
\end{tabular}

Research Question 3: Will there be a significant relationship between the cognitive component of job satisfaction and empathic behaviour among health care workers?

From the result of Table 3, the coefficient of determination is 0.18 , which means there is a small positive relationship between the cognitive component of job satisfaction and empathic behaviour among health care workers. The cognitive component of job satisfaction, therefore, accounted for $18 \%$ of the variance in empathic behaviour.

Table 3. Analysis of the relationship between the cognitive component of job satisfaction and empathic behaviour among health care workers

\begin{tabular}{lllllll}
\hline Variable & $\mathbf{N}$ & Mean & SD & $\mathbf{r}$ & $\mathbf{r}^{2}$ & Decision \\
\hline $\begin{array}{l}\text { Cognitive Component } \\
\text { of Job Satisfaction }\end{array}$ & 1,144 & 3.11 & 0.56 & & & Small \\
Empathic Behaviour & & 3.85 & 0.44 & & & Relationship \\
\hline
\end{tabular}

Research Question 4: Will there be a significant relationship between the behavioural component of job satisfaction and empathic behaviour among health care workers?

From the result of Table 4, the coefficient of determination is 0.26 , which means there is a small positive relationship between the behavioural component of job satisfaction and empathic behaviour among health care workers. Hence, the behavioural component of job satisfaction accounted for $26 \%$ of the variance in empathic behaviour.

Table 4. Analysis of the relationship between the behavioural component of job satisfaction and empathic behaviour among health care workers

\begin{tabular}{lllllll}
\hline Variable & $\mathbf{N}$ & Mean & SD & $\mathbf{r}$ & $\mathbf{r}^{2}$ & Decision \\
\hline $\begin{array}{l}\text { Behavioural Component } \\
\text { of Job Satisfaction }\end{array}$ & 1,144 & 3.34 & 0.67 & & & Small \\
Empathic Behaviour & & 3.85 & 0.44 & & & Relationship \\
\hline
\end{tabular}

\section{Analysis of hypotheses}

Hypothesis 1: There is no significant relationship between job satisfaction and empathy among health care workers.

Table 5. Analysis of the relationship between job satisfaction and empathy among health care workers

\begin{tabular}{|c|c|c|c|c|c|}
\hline Model & Sum of Square & df & Mean Square & $\mathbf{F}$ & $p$ \\
\hline Regression & 67.568 & 1 & 67.568 & & \\
\hline Residual & 154.012 & 1,142 & .135 & 501.017 & $.000^{*}$ \\
\hline Total & 221.580 & 1,143 & & & \\
\hline \multicolumn{6}{|c|}{ Variables in Equation } \\
\hline \multirow{2}{*}{ Model } & \multicolumn{2}{|c|}{ Unstandardized Coefficient } & Standardized Coefficient & \multirow{2}{*}{$\mathbf{t}$} & \multirow{2}{*}{$p$} \\
\hline & B & Std. Error & Beta & & \\
\hline Constant & 2.060 & .081 & & 25.485 & .000 \\
\hline Job Satisfaction & .540 & .024 & .552 & 22.383 & .000 \\
\hline
\end{tabular}

Note. $\alpha=0.05, \mathrm{R}=0.552$, R-Square $=0.305$; Dependent Variable: Empathy; * Predictors (Constant): Job Satisfaction

Table 5 shows a regression analysis of the relationship between job satisfaction and empathy among health care workers. Result shows that $\mathrm{F}(1,1143)=501.017, p<.05$. The null hypothesis is therefore rejected. This means that there is a significant relationship between job satisfaction and empa- thy among health care workers. Job satisfaction, therefore, accounted for $55 \%$ of the variance in empathic behaviour, as shown in the Beta value of 0.55 .

Hypothesis 2: There is no significant relationship between the affective component of job satisfaction and empathy 
among health care workers.

From Table $6, \mathrm{~F}(1,1143)=205.185, p<.05$. The null hypothesis is therefore rejected, an indication that there is a significant relationship between the affective component of job satisfaction and empathy among health care workers. As shown in the Beta of 0.39 , the affective component of job satisfaction, therefore, account for $39 \%$ variance in empathy among health care workers.

Hypothesis 3: There is no significant relationship between the cognitive component of job satisfaction and empathic behaviour among health care workers.

Table 7 shows $\mathrm{F}(1,1143)=247.438, p<.05$. Hence, the null hypothesis is rejected. This means that there is a significant relationship between the cognitive component of job satisfaction and empathic behaviour among health care workers. The Beta value of 0.42 indicates that the cognitive component of job satisfaction accounted for $42 \%$ of the variance in empathy among health care workers.

Table 6. Analysis of the relationship between the affective component of job satisfaction and empathy among health care workers

\begin{tabular}{|c|c|c|c|c|c|}
\hline Model & Sum of Square & df & Mean Square & $\mathbf{F}$ & $\bar{p}$ \\
\hline Regression & 33.748 & 1 & 33.748 & & \\
\hline Residual & 187.832 & 1,142 & .164 & 205.185 & $.000^{*}$ \\
\hline Total & 221.580 & 1,143 & & & \\
\hline \multicolumn{6}{|l|}{ Variables in Equation } \\
\hline \multirow{2}{*}{ Model } & \multicolumn{2}{|c|}{ Unstandardized Coefficient } & Standardised Coefficient & \multirow{2}{*}{$\mathbf{t}$} & \multirow{2}{*}{$p$} \\
\hline & B & Std. Error & Beta & & \\
\hline Constant & 2.479 & .097 & & 25.627 & .000 \\
\hline $\begin{array}{l}\text { Affective Component of Job } \\
\text { Satisfaction }\end{array}$ & .391 & .027 & .390 & 14.324 & .000 \\
\hline
\end{tabular}

Note. $\alpha=0.05, \mathrm{R}=0.390, \mathrm{R}$-Square $=0.152$; Dependent Variable: Empathy; * Predictors (Constant): Affective Component of Job Satisfaction

Table 7. Analysis of the relationship between the cognitive component of job satisfaction and empathic behaviour among health care workers

\begin{tabular}{|c|c|c|c|c|c|}
\hline Model & Sum of Square & df & Mean Square & $\mathbf{F}$ & $p$ \\
\hline Regression & 39.460 & 1 & 39.460 & & \\
\hline Residual & 182.120 & 1,142 & .159 & 247.438 & $.000^{*}$ \\
\hline Total & 221.580 & 1,143 & & & \\
\hline \multicolumn{6}{|l|}{ Variables in Equation } \\
\hline \multirow{2}{*}{ Model } & \multicolumn{2}{|c|}{ Unstandardized Coefficient } & Standardised Coefficient & $\mathbf{t}$ & $p$ \\
\hline & B & Std. Error & Beta & & \\
\hline Constant & 2.818 & .067 & & 42.124 & .000 \\
\hline $\begin{array}{l}\text { Cognitive Component of } \\
\text { Job Satisfaction }\end{array}$ & .333 & .021 & .422 & 15.730 & .000 \\
\hline
\end{tabular}

Note. $\alpha=0.05, \mathrm{R}=0.422$, R-Square $=0.178$; Dependent Variable: Empathy; * Predictors (Constant): Cognitive Component of Job Satisfaction

Hypothesis 4: There is no significant relationship between the behavioural component of job satisfaction and empathic behaviour among health care workers.

Table 8 shows $\mathrm{F}(1,1143)=391.932, p<.05$. Hence, the null hypothesis is rejected. This means that there is a significant relationship between the behavioural component of job satisfaction and empathic behaviour among health care workers. As indicated in the Beta value of 0.51, the behavioural component of job satisfaction, therefore, accounted for $51 \%$ of

Published by Sciedu Press

the variance in empathy among health care workers.

Hypothesis 5: There is no significant moderating impact of gender on the relationship between affective, cognitive and behavioural components of satisfaction and emphatic behaviour among health care workers.

As shown in Table 9, the relationship between affective, cognitive, behavioural components of satisfaction and empathic behaviour was conducted as well as the moderating impact of gender. The result is presented in a correlation matrix. As 
shown in the table, the relationship between affective component and empathic behaviour $=0.39$, cognitive component and empathic behaviour $=0.42$, and cognitive component $=$ 0.51 , relationship between behavioural component and empathic behaviour $=0.51$, gender and empathic behaviour $=$ 0.08 . The relationship between gender and other independent variables shows that gender and affective component $=$ 0.07 , gender and cognitive component $=0.09$, gender and behavioural component $=0.12$. Based on the fact that the moderator variable had no significant relationship with all the independent variables as well as the dependent variable, the null hypothesis is therefore accepted. This means that there is no significant moderating impact of gender on the relationship between affective, cognitive and behavioural components of satisfaction and empathic behaviour among health care workers. The moderating impact of the variable is presented as shown in Figure 1.

Table 8. Analysis of the relationship between the behavioural component of job satisfaction and empathic behaviour among health care workers

\begin{tabular}{|c|c|c|c|c|c|}
\hline Model & Sum of Square & df & Mean Square & $\mathbf{F}$ & $p$ \\
\hline Regression & 56.615 & 1 & 56.615 & & \\
\hline Residual & 164.964 & 1,142 & .144 & 391.932 & $.000^{*}$ \\
\hline Total & 221.580 & 1,143 & & & \\
\hline \multicolumn{6}{|l|}{ Variables in Equation } \\
\hline \multirow{2}{*}{ Model } & \multicolumn{2}{|c|}{ Unstandardized Coefficient } & Standardized Coefficient & \multirow{2}{*}{$\mathbf{t}$} & \multirow{2}{*}{$p$} \\
\hline & B & Std. Error & Beta & & \\
\hline Constant & 2.746 & .057 & & 48.107 & .000 \\
\hline $\begin{array}{l}\text { Behavioural Component of } \\
\text { Job Satisfaction }\end{array}$ & .331 & .017 & .505 & 19.797 & .000 \\
\hline
\end{tabular}

Note. $\alpha=0.05, \mathrm{R}=0.505, \mathrm{R}-\mathrm{Square}=0.256$; Dependent Variable: Empathy; ${ }^{*}$ Predictors (Constant): Behavioural Component of Job Satisfaction

Table 9. The moderating impact of gender on the relationship between affective, cognitive and behavioural components of satisfaction and empathic behaviour among health care workers

\begin{tabular}{|c|c|c|c|c|c|c|c|}
\hline Variables & Mean & SD & $\begin{array}{l}\text { Affective } \\
\text { Component }\end{array}$ & $\begin{array}{l}\text { Cognitive } \\
\text { Component } \\
\end{array}$ & $\begin{array}{l}\text { Behavioural } \\
\text { Component }\end{array}$ & $\begin{array}{l}\text { Empathic } \\
\text { Behaviour }\end{array}$ & Gender \\
\hline Affective Component & 3.52 & 0.44 & & & & & \\
\hline Cognitive Component & 3.11 & 0.56 & 0.51 & & & & \\
\hline Behavioural Component & 3.34 & 0.67 & 0.43 & 0.49 & & & \\
\hline Empathic Behaviour & 3.85 & 0.44 & 0.39 & 0.42 & 0.51 & & \\
\hline Gender & 1.71 & 0.45 & 0.07 & 0.09 & 0.12 & 0.08 & \\
\hline
\end{tabular}

Note. 0.05 level of significance

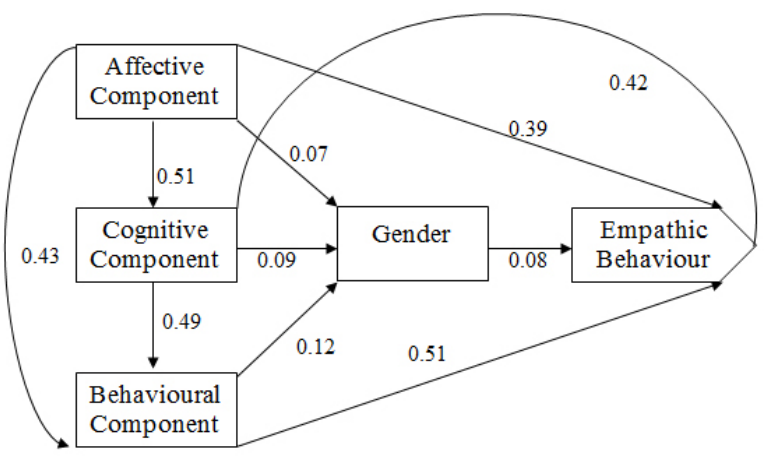

Figure 1. Path analysis model of the moderating impact of gender on the relationship between affective, cognitive and behavioural components of satisfaction and emphatic behaviour among health care workers

\section{DiscuSSION}

Based on the data analysed in the study, several findings emerged. The first research question which sought to find out if there is any relationship between job satisfaction and empathy among health care workers found that a moderate positive relationship exists between job satisfaction and empathic behaviour among health care workers. The corresponding hypothesis showed that the relationship is significant. This finding implied that job satisfaction can influence empathic behaviour among health care workers. A satisfied worker is therefore likely to be more empathic towards his/her patients than an unsatisfied health worker. This finding is in line with the finding of Sand, ${ }^{[18]}$ which revealed that long term satisfaction is related to a high level of empathy in nursing 
staff.

The second research question which sought to examine the type of relationship that exists between the affective component of job satisfaction and empathic behaviour among health care workers found that a small positive relationship exists between the two variables. The hypothesis tested in line with the research question shows that the relationship between the two variable is significant with a $95 \%$ confidence level. This implies that empathic behaviour is likely to be influenced by the affective component of job satisfaction. Individuals with positive affective job satisfaction are more likely to show empathic behaviour towards their patients than individuals with negative affective job satisfaction. The finding shows that there is no significant relationship between gender and empathy among health care workers in Nigeria. This finding is an indication that gender does not moderate the relationship between job satisfaction and empathic behaviour among health care workers.

The third research question which sought to find out the relationship that exists between the cognitive component of job satisfaction and empathic behaviour among health care workers showed that the relationship that exists between the two variables is a small positive. The corresponding hypothesis shows that the relationship is significant. This means that the cognitive component of job satisfaction is very likely to influence empathic behaviour among health care workers. Hence, an individual whose job expectation is same with experience is more likely to show empathic behaviour towards his/her patient than an individual whose job experience is below his/her job expectation. This finding is consistent with Tekell, ${ }^{[16]}$ who asserts that if an employee expects a certain level of autonomy in the way he works and is being micromanaged, the discrepancy between expected and perceived autonomy may lead to thoughts of dissatisfaction.

The fourth research question which examined the extent of the relationship that exists between the behavioural component of job satisfaction and emphatic behaviour among health care workers shows that a small positive relationship exists between the two variables. A corresponding hypothesis tested shows the relationship to be significant. A high behavioural component of job satisfaction is therefore positively associated with a high level of empathic behaviour among health care workers. This implies that health care workers who experience a high level of behaviour component of job satisfaction are more likely to show empathic behaviour towards their patients than employees with a low level of behavioural component of job satisfaction.

Analysis of the fifth hypothesis, which examined the moderating impact of gender on the relationship between affective, cognitive and behavioural components of satisfaction and emphatic behaviour among health care workers showed that gender does not moderate the relationship among the variables. This implied that the relationship between the three components of job satisfaction and empathic behaviour is not likely to be moderated by gender. Male and female health workers therefore, respond in similar ways to job satisfaction in connection with empathic behaviour towards their patients.

\section{CONCLUSION/RECOMMENDATIONS}

Based on the findings of the study, it thus concluded that job satisfaction is most likely to positively influence empathic behaviour among health workers towards their patients. This is true for all the three components of job satisfaction; affective, cognitive and behavioural components. Based on this finding the following are therefore recommended for proper action:

(1) That government should provide adequate facilities that will ease the job of health care workers

(2) Salary and other wages should be paid regularly and as at when due

(3) Management should provide a conducive working environment which will motivate the staff

\section{The implication of the study to health care providers}

The data obtained in this study and the findings have shown that indeed, job satisfaction is a significant predictor of empathic behaviour, which is a major requirement for people who work in health care. This is because people who seek their services oftentimes need to be shown some level of warmth, acceptance, understanding and patience. The implication is that managers of health care should strive to provide the needed support for health care workers so that they can derive satisfaction from their jobs. They should be adequately motivated and all necessary working tools should be provided. This will go a long way ensuring job satisfaction among them.

\section{CONFlicts OF InTEREST Disclosure}

The authors declare no conflicts of interest. 


\section{REFERENCES}

[1] Hojat M, Gonnella J, Mangione S, et al. Physician empathy in medical education and practice: Experience with the Jefferson scale of physician empathy. Seminars in Integrative Medicine. 2003; 1(1): 25-41. https : //doi.org/10.1016/S1543-1150(03)00002-4

[2] Sudeh CS, Hole AR, Mead N, et al. What patients want from primary care consultations: A discrete choice experiment to identify patients' priorities. Annals of Family Medicine. 2008; 6: 107-115. PMid:18332402. https ://doi.org/10.1370/afm. 816

[3] Figley CR. Compassion fatigue: Psychotherapists' chronic lack of self-care. Journal of Clinical Psychology. 2002; 58: 1433-1441. PMid:12412153. https://doi.org/10.1002/jclp.10090

[4] Morse JM, Bottorff J, Anderson G, et al. Beyond empathy: Expanding expressions of caring. Journal of Advanced Nursing. 1992; 1: 809-821. PMid:1644977. https://doi.org/10.1111/j.1365 $-2648.1992 . t b 02002 . x$

[5] Spector PE. Industrial \& organizational psychology (2nd ed.). New York: John Wiley \& Sons. 2000.

[6] Ellickson MC, Logsdon K. Determinants of job satisfaction of municipal government employees. Public Personnel Management. 2002 31(3): 343-358. https ://doi.org/10.1177/00910260020310 0307

[7] Parvin MM, Kabir MMN. Factors affecting employee job satisfaction in the pharmaceutical sector. Australian Journal of Business and Management Research. 2011; 1(9): 113-123.

[8] Reilly CR. Organizational Behavior. Annual Review of Psychology. 1991; 427-458. PMid:19090761. https ://doi.org/10.1146/an nurev.ps.42.020191.002235

[9] Wanous JP, Lawler EE. Measurement and Meaning of Job Satisfaction. Journal of Applied Psychology. 1972; 95-105. https: //doi.org/10.1037/h0032664

[10] Watson D, Clark LA, Tellegen A. Development and validation of brief measures of positive and negative affect: The PANAS scales. Journal of Personality and Social Psychology. 1988; 54(6): 1063 1070. PMid:3397865. https://doi .org/10.1037/0022-3514. 54.6 .1063

[11] Weiss HM, Cropanzano R. Affective events theory: A theoretical discussion of the structure, causes, and consequences of affective experiences at work. Research in Organizational Behavior. 1996; 18: $1-74$
[12] Yik MSM, Russell JA. Predicting the big two of affect from the big five of personality. Journal of Research in Personality. 2001; 35 : 247-277. https ://doi.org/10.1006/jrpe.2001.2322

[13] Watson D, Clark LA. Negative affectivity: The disposition to experience aversive emotional states. Psychological Bulletin. 1984; 96: 465-490. PMid:6393179. https ://doi .org/10.1037/0033-290 9.96 .3 .465

[14] Schaubroeck J, Ganser DC, Fox ML. Dispositional affect and workrelated stress. Journal of Applied Psychology. 1992; 3: 322-335. PMid:1601824. https://doi.org/10.1037/0021-9010.77.3 .322

[15] Weiss HM. Conceptual and empirical foundations for the study of affect at work. In Lord, Klimoski, \& Kafner (Eds). Emotions in the workplace: Understanding the structure and role of emotions in organizational behaviour (p.20-63) San Francisco, CA: Josey-Bass. 2002.

[16] Tekell JK. Affective and cognitive components of job satisfaction: Scale development and initial validation. Unpublished M.Sc. Dissertation, University of North Texas. 2008.

[17] Hulin CL, Judge TA. Job attitudes. In W.C. Borman, R. Klimoski, and D. Ilgen (Eds.), Handbook of psychology: Industrial and organizational psychology. New York: Jon Wiley \& Sons, Inc. 2003. 12: 255-276.

[18] Sand A. Nurses' personalities, nursing-related qualities and work satisfaction: a 10-year perspective. Journal of Clinical Nursing. 2003; 12(2): 177-187. PMid:12603549. https://doi.org/10.1046/j . 1365-2702.2003.00729.x

[19] Larson EB, Yao X. Clinical empathy as emotional labour in the patient-physician relationship. JAMA. 2005; 293: 1100-1106. PMid:15741532. https ://doi.org/10.1001/jama.293.9.110

[20] Mousavi SH, Yarmohammaid S, Norsat AB, et al. The relationship between emotional intelligence and job satisfaction of physical education teachers. Annals of Biological Research. 2012; 3(2): 780-788.

[21] Homburg C, Stock RM. Exploring the conditions under which salesperson work satisfaction can lead to customer satisfaction. Psychol. Market. 2005; 22: 393-420. https : //doi.org/10.1002/mar. 20 065

[22] Lombardo B, Eyre C. Compassion Fatigue: A Nurse's Primer. Online Journal of Issues in Nursing. 2011; 16(1): 1-7. 